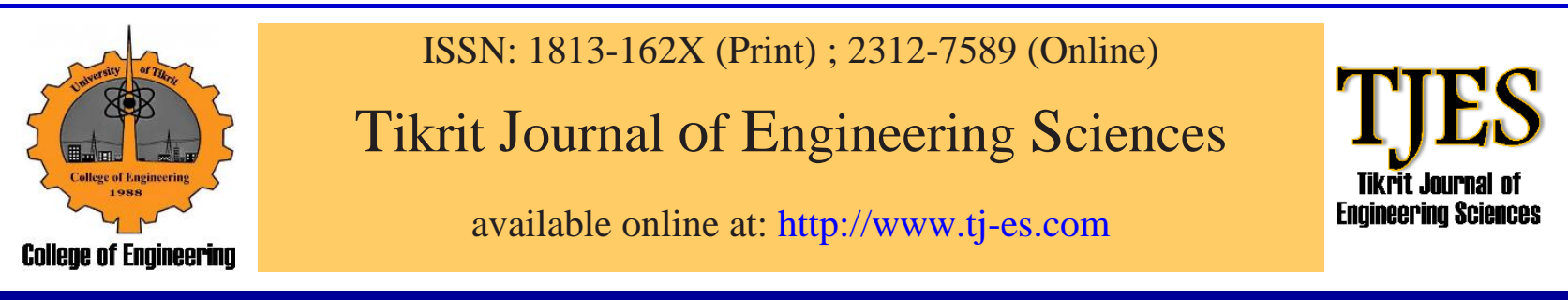

\title{
Optimum Tendon Placement for Post Tensioned S.S. Beam with Variable Eccentricity
}

Civil Engineering Department Engineering College Mosul University

Mosul, Iraq

\section{A B S T R A C T}

A challenging problem for a direct search design methods was introduced in this work. Pattern Search PS method was used to find the optimum designed section of a prestressed simply supported post tensioned beam with variable tendon eccentricity. Flexural and geometrical design constraints were used to get the optimum sectional properties of the beam. Then, new constraints concerning the placement of the tendon through the longitudinal section of the beam were introduced and involved through finding the optimum results. A single objective function was used since a multi objective optimization procedure could not be run with nonlinear constraints, and optimizing a post tensioned beam with variable eccentricity represents a highly constraints problem. Another optimization method was used here only to check the validity of the procedure adopted using PS, the results were compared for the methods and a good agreement were found between them. Apparently, using the additional constraints of the tendon placement causes a lot of difficulties to find the optimum results, as it was noticed through the elapsed time of the solution, although, both methods gave a reliable and practical optimum values, and this is due to the robust use of the design constraints to limit the optimum designed variables within the ACI code 2011 limits. Increasing the efficiency of the solution was gained through using a lot of design constraints, in addition to the basic design constraints needed in the flexural design, to avoid trapping in local optima.

(c) 2018 TJES, College of Engineering, Tikrit University

DOI: http://dx.doi.org/10.25130/tjes.25.1.05

التموضع الامثل للاوتار مسبقة الجها والثد ذات المسار المتغير في الجسور بسيطة الاسناد

تتناول هذه الدر اسة مشكلة تحديد التصميم الامثل للحديد مسبق الجها وتموضعه بمسار متغير أمثل داخل العتبة الخرسانية بسبطة الاسناد باستخدام احدى طرق الـ Direct

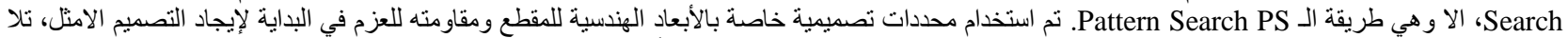

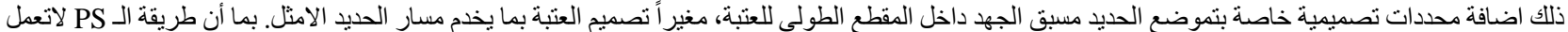

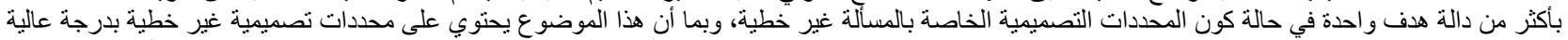

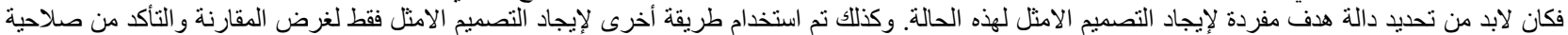

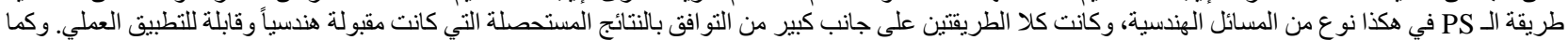

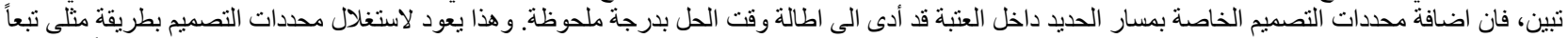
للمدونة المستخدمة الـ ACI Code 2011 بحيث تزيد من منانة الطريقة المستخدمة ودقتها في ايجاد التصميم الامثل بدون أن تعلق بنقطة امثليه غير صحيحة نسبياً.

\section{INTRODUCTION}

Since the main goal of this study is finding the optimum tendon placement for a simply supported beam with variable eccentricity, a highly constrained design procedure should be adopted. Using the objective function as design constraints will be used here because a multi objective design could not be performed using Pattern Search PS procedure with nonlinear design constraints.

An optimum designed section will be found first with the optimum sectional properties, and then the design 
procedure took a turn to involve the eccentricity of the tendon through the span of the beam. This of course will be much easier if the tendon is placed with constant eccentricity along the longitudinal section of the beam. But, since the beam is simply supported which makes the critical section lies at the middle and there is a need to increase the eccentricity there, but at the same time, this will cause a highly eccentric tendon at support too, causing an unbalanced stress at the top fibers of the cross section. So, decreasing the eccentricity at the support section is necessary to reduce the additional stresses, and this can only be happening by using a variable eccentricity for the used tendon through the designed section.

In order to achieve such a hard goal with nonlinear restrictions according to the design code (ACI code 2011) [1]. A robust optimum design method should be used to get convenient results. P.S procedure had proved its efficiency through many engineering problems with different conditions of the design constraints. So, it will be a good choice to be used in such a challenging problem as putting a tendon optimally through an optimally designed post-tensioned simply supported beam and keeping the eccentricity of the tendon variable along the span.

A cost optimization of a prestressed concrete bridge was done before using genetic algorithms by Aydin and Ayvaz [2]. The design variables for this study were the number of spans, and the cross sectional properties. A modified GAs was used to find the optimum solution of a pre-tensioned I-girder, working stresses, geometry and ductility were used as design constraints. Gas was found to be an effective method in optimizing the cost of prestressed bridges.

De Castilhoa et al. [3] used modified Gas to minimize the production costs of slabs using precast prestressed concrete joists, in this study a penalty function was used in the constraints violation. Describing the multiple costs was involved in these slabs production, and one objective function was used to combine them. Two objective functions were simultaneously satisfied in the optimization of prestressed concrete structures by Lounis and Cohn [4] A post-tensioned floor slab and a pre-tensioned highway bridge system were solved using the projected Lagrangian algorithm, also Pareto optima was used to achieve the trading procedure between the two objectives (minimum cost and minimum initial camber). A more rational solution was achieved using this procedure than finding the optimum solution using each single objective function alone.

The layout and the profile of post tensioning tendons were presented by Aalami [5] with the layout of the supplemental non prestressed reinforcement for post tensioned floor systems. This technical note declares that the placement of passive reinforcement covers both minimum requirements of the codes for a flat slab floor system and the requirements to meet strength demand, and minimizing the risk to avoid openings by limiting the horizontal curvature of the tendon, and avoiding the sharp vertical curvature to minimize flexural stresses in the strand wires.

\section{OPTIMUM TENDON DESIGN}

Using a variable tendon eccentricity in simply supported beam is better than using a tendon with constant eccentricity along the span, that is because the critical section for this case lies at the middle section of the beam and using a constant eccentricity will cause a large tensile stresses at the top fibers at support with no external superimposed moment to reduce it, and this makes the critical section for constant eccentricity of simply supported beam lies at the support section.

Now, after confirming that the beam should be designed with variable tendon eccentricity, the design procedure will take place by choosing the suitable objective function for a reliable design. For sure, every objective function will not conclude its purpose if the designed section was not subjected to a design code, to achieve that, the design procedure should be limited with so many design constraints (according to the designer) to make sure that the optimum results are feasible and capable of handling the applied conditions.

Finally, making sure that all the design constraints and the objective function are involved in the solution in form of what is called design variables. So, before start the solution, the designer must specify the design variables of the problem, that the solver (PS in this case) will start a trading procedure between the values of the design variable to get the optimum solution for the problem and subjecting these values to the design constraints specified previously to make sure that none of the optimum results will violate the design constraints. Definitely, the designer could use a penalty function with certain limits for the violation of the constraints that will be a factor in choosing the best optimum design results according to the violation of each solution. The penalty function will not be used here, the only allowed optimum solution will be the one with the minimum constraints violation or zero constraints violation.

In the present work, the optimum designed section was gained with applied constraints concerning only flexural design and the limitation of the allowed stresses at the extreme fibers of the cross section which were used through the design constraints explained later. Then, a new modification to the solution was entered, and that is the optimum placement of a variable tendon eccentricity through the longitudinal section of the beam. Also, getting the optimum placement of a tendon should be subjected to a special design constraints concerning geometrical and design limitation to ensure that this optimum placement of the tendon will not cause any violation to the original optimum design of the post-tensioned beam.

According to Nawi [6] and Naaman [7], the actual fiber stresses at the extreme ends of the cross section should not exceed the following allowable values of stresses depending on the location of the stresses and the loading stage.

$f_{c i}$ : Maximum allowable compressive stress immediately after transverse and before losses.

$f_{t i}$ : Maximum allowable tensile stress immediately after transverse and before losses.

$f_{c}$ : Maximum allowable compressive stress immediately after losses at service load.

$f_{t}$ : Maximum allowable tensile stress immediately after losses at service load.

For designing this beam, these values were taken to be as follow:

$f_{c i}=0.6 f_{c i}^{-}$ 
$f_{t i}=3 \sqrt{f_{c i}^{-}}$and $f_{t i}=6 \sqrt{f_{c i}^{-}}$and support

$f_{c}=0.45 f_{c}^{-}$

$f_{t}=12 \sqrt{f_{c}^{-}}$

where:

$f_{c i}^{-}=0.75 f_{c}^{-}$

\section{OPTIMUM DESIGN PROCEDURE}

Ps mesh adaptive search (MADS) is one of the direct search methods, the objective function's gradient is not necessary here. Potential solutions were represented by a sequence of points, and then an optimum point will be approached through many steps. A set of points at each step called mesh, lying around the point from the previous step, will be searched using PS. The formation of this mesh is found by adding a pattern (a scalar multiple of a set of vectors) to the current point, the searched points at each iteration will be specified by these patterns. The selection of the next and the current points is shown in Fig. 1 according to the specified objective function. By selecting the vectors that defines the mesh randomly using (MADS), the new point founds by PS that improves the objective function will be taken as the current point through the next step [8]. A main difference between this method and GAs is that by using PS, a starting point for the solution should be specified prior to the solution, while GAs depends on searching many different points at the same time.

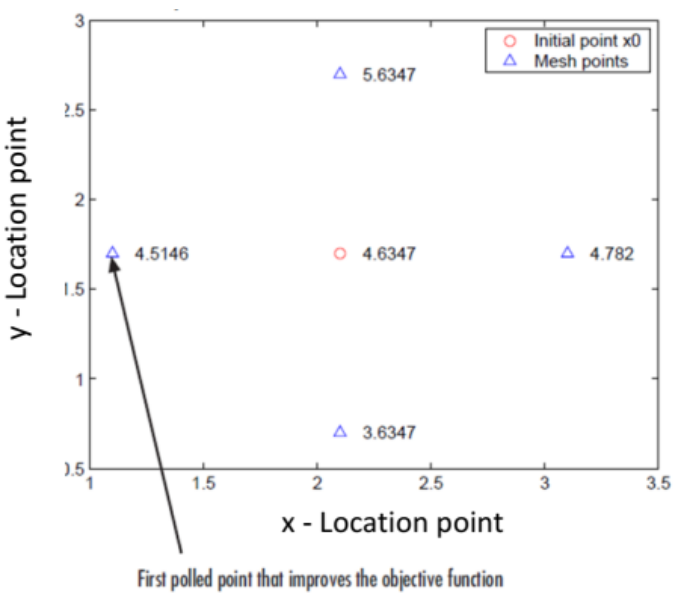

(a) Initial point

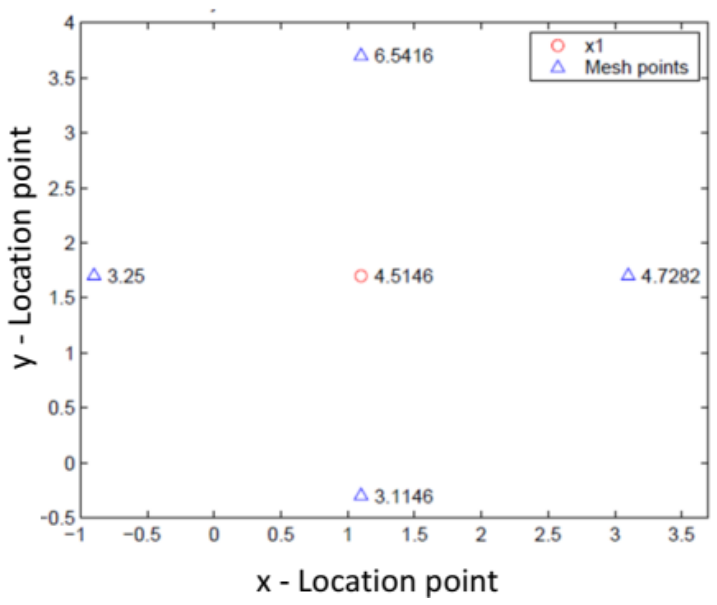

(b) Next point

Fig. 1. Objective function values at $x 0 \times 1$ and mesh points [8].
The number of vectors that will be randomly selected here using (MADS) will be $2 \mathrm{~N}$ or $\mathrm{N}+1$, depending on the poll method choice as it will be explained later.

The GAs solver generates a population of chromosomes that stands for potential solution to the problems, each chromosome contains several genes that represents the design variables of the problem, these chromosomes (solutions) lies within a certain limits specified by the designer. The chromosomes forming the generation is ranked according to their fitness, then a new modified generation is created using many steps such as selection (to choose the best chromosomes to continue through the following design steps of the procedure), crossover ( an exchange procedure between each two selected chromosomes to create a new modified chromosomes that represents a better solution to the problem), and a mutation (which is used to flip the value of one randomly chosen gene from zero to one or one to zero according to the encoding system used to transform the variables from its pheno type the geno type).

Elitism could be used at this stage, which allows the most fitted chromosomes to pass through the next generation without passing the main steps of the solution (selection, crossover and mutation).

All of these steps to create the new modified generation that represents a new modified solution to the problem, will be done according the limitation of the design constraints specified by the designer to subject the solution to the design code, otherwise, the new solution will not be practical or reliable. A decoding procedure (using the binary system) took place after that to transform the solution from the geno type to the pheno that represents the final design variables of the problem.

This whole design procedure will be solved repeatedly until the optimum solution is gained with the minimum objective function and the least constraints violation, the solver will be stopped according to one of the stopping criteria specified by the used procedure [8].

\section{PS design options}

As soon as a better point is found, the poll should stops using an additional option to the classical procedure of PS, which is a "complete poll" option that was taken to be on. Scheduling the evaluations will be at once through searching in parallel with parfor. After the evaluations are returned, the computing continues. Noticing that, halting the evaluations after scheduling is not that easy [8]. Also, setting the Maximum Numbers of Iterations and Function Evaluations to " $2000 \times$ number of variables" using "maxfunevals", to specify the maximum number of objective function evaluations. And for the "pollmethod" option, a "madspositivebasis2n" was chosen to define the Polling strategy used in pattern search, this method is slower than the "GPSPositiveBasisNp1" and "MADSPositiveBasisNp1" methods. But using this method performs a more thorough search.

Finally, if a point was polled once and it does not have to be polled again, a record of the already polled points should be kept using the "cache" option, which is also used to speed up the algorithm if the objective function takes a long time to be computed [8] 


\subsection{Optimum Design of Prestressed Beam with variable Tendon}

\section{- Objective function}

It is difficult to run a multi objective function in the Matlab PS solver directly with a highly constrained problem especially with nonlinear design constraints, and so is the GAs solver. So, in order to run such a problem, a single optimization procedure should be adopted here. And since the first sectional property cross the mind in selecting the best designed cross section is the minimum section modulus, this value was chosen to be the objective function of the optimum solution, Eq. (1).

$$
S^{t}-\frac{(1-\gamma) M_{D}+M_{S D}+M_{L}}{\gamma f_{t i}-f_{c}}
$$

In addition to that, this value will be used as a design constraint with $\mathrm{S}_{\mathrm{b}}$ to ensure that the section modulus is limited with the applied moments and stresses.

\section{- Design variables}

Any optimization procedure should have at least two design variables, that's so a trading procedure could take place between them in order to get the optimum values for both of them that result an optimum objective function [9].
Since the present woke include finding the optimum designed section of a variable tendon post tensioned simply supported beam, a basic section property should be involved in design as a design variable, these design variables in this case were chosen to be as follow:

I: Moment of inertia of the designed cross section ( $\left.\mathrm{in}^{4}\right)$.

h: The height of the cross section of the beam (in).

$\mathrm{c}_{\mathrm{t}}$ : Distance from the extreme top fibers to the neutral axis (in).

$c_{b}$ : Distance from the extreme bottom fibers to the neutral axis (in).

$\mathrm{A}_{\mathrm{c}}$ : Area of the cross section $\left(\mathrm{in}^{2}\right)$.

Other optimum design variable, Fig. (2), will be calculated with accordance to its basic design variables and so on, such as:

$\mathrm{S}_{\mathrm{t}}$ : Top section modulus $\left(\mathrm{in}^{3}\right)$, is represented by $\left(\mathrm{I} / \mathrm{c}_{\mathrm{t}}\right)$.

$\mathrm{S}_{\mathrm{b}}$ : Bottom section modulus $\left(\mathrm{in}^{3}\right)$, is represented by $\left(\mathrm{I} / \mathrm{c}_{\mathrm{b}}\right)$. $\mathrm{k}_{\mathrm{t}}$ : Upper kern point (in), is represented by $\left(\mathrm{r}^{2} / \mathrm{c}_{\mathrm{b}}\right)$, $\left(\left(\mathrm{I} / \mathrm{A}_{\mathrm{c}}\right) / \mathrm{c}_{\mathrm{b}}\right)$.

$\mathrm{k}_{\mathrm{b}}$ : Lower kern point (in), is represented by $\left(\mathrm{r}^{2} / \mathrm{ct}\right)$, $\left(\left(\mathrm{I} / \mathrm{A}_{\mathrm{c}}\right) / \mathrm{c}_{\mathrm{t}}\right)$.

$r^{2}$ : Radius of gyration of the cross section $\left(\mathrm{in}^{2}\right)$, is represented by $\left(\mathrm{I} / \mathrm{A}_{\mathrm{c}}\right)$.

Any other equation used in the optimum solution, all of its variables will be represented by the original basic design constraints, such as $\left(\mathrm{e}_{\mathrm{c}}, \mathrm{e}_{\mathrm{e}}, \mathrm{e}_{\mathrm{t}}^{-}, \mathrm{e}_{\mathrm{b}}{ }^{-} \ldots\right)$.

pper limit, permitting tension

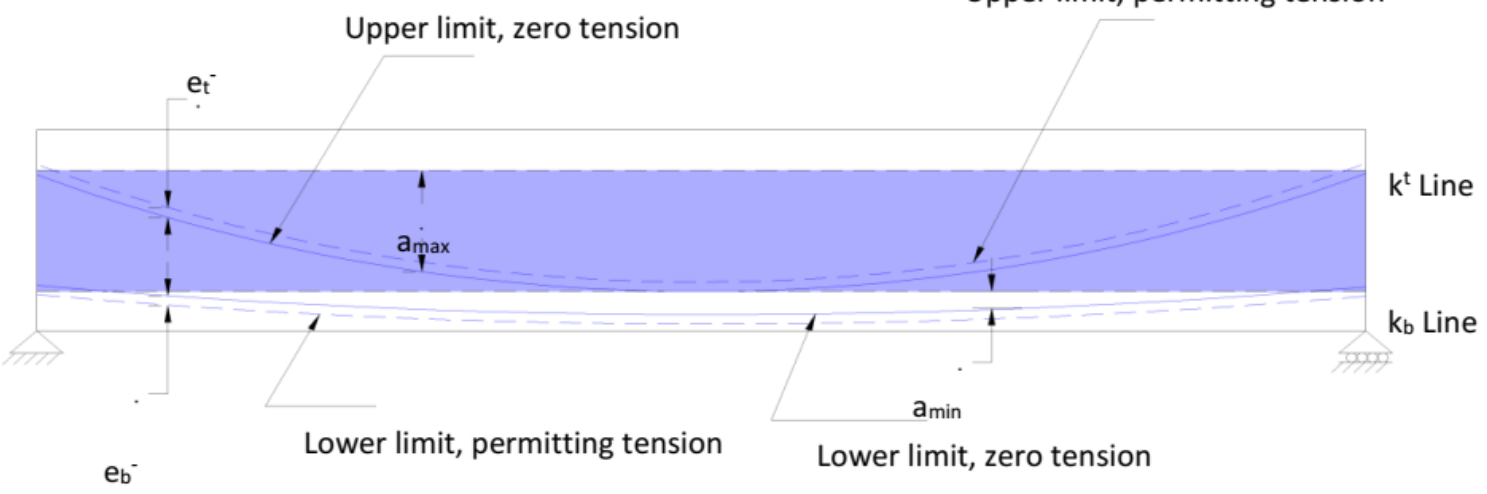

Fig. 2. Optimum envelope in concrete extreme fiber [6].

\section{- Design constraints}

In order to get the optimum design results, limitations are required to the design procedure, whether a pattern search or genetic algorithms approach or any other optimization approach will be adopted. In this study, limiting the section modulus $\left(\mathrm{S}_{\mathrm{t}}\right.$ and $\left.\mathrm{S}_{\mathrm{b}}\right)$ will be considered as design constraints in addition to using these sectional properties as an objective function, Eq. (2) shows the limitation of the section modulus for beams with variable tendon eccentricity.

$$
\left.\begin{array}{rl}
1-\frac{S^{t}}{\frac{(1-\gamma) M_{D}+M_{S D}+M_{L}}{\gamma f_{t i}-f_{c}}} & \leq 0.0 \\
1-\frac{S_{b}}{\frac{(1-\gamma) M_{D}+M_{S D}+M_{L}}{f_{t}-\gamma f_{c}}} & \leq 0.0
\end{array}\right\}
$$

Since for simply supported beam, the maximum eccentricity lies at mid-span section which is the critical section for beams prestressed with harped or draped tendons, the value of this eccentricity $\left(\mathrm{e}_{\mathrm{c}}\right)$ will be limited using Eq. (3):

$\left[e_{c}-\left(f_{t i}-f_{c i}^{-}\right) \frac{S^{t}}{P_{i}}+\frac{M_{D}}{P_{i}}\right]=0.0$

The stress of concrete at the centroid cgc level of the cross section at transfers will be limited by the following equation:

$\left[f_{c i}^{-}-\left(f_{t i}-\frac{c^{t}}{h}\right)\left(f_{t i}-f_{c i}\right)\right]=0.0$

The next equation was used to ensure that the tensile stress at the top fibers of the cross section at transfers within the allowable limits, in order to get the eccentricity $\left(\mathrm{e}_{\mathrm{e}}\right)$ of the tendon at support section. 


$$
\left\{f_{b}-\left[-\frac{f_{i}}{A_{c}}\left(1+\frac{e_{e} c_{b}}{r^{2}}\right)\right]+0.0\right\}=0.0
$$

In order to ensure that the extreme fiber stresses in the cross section (top and bottom) does not exceed the allowable values for stresses listed before, the following equations will be used:

$$
\left\{\left[\frac{-\frac{P_{i}}{A_{c}}\left(1-\frac{e_{e} c^{t}}{r^{2}}\right)-\frac{M_{D}}{S^{t}}}{f_{t i}}\right]-1\right\} \leq 0.0
$$

The previous equation is used to ensure that the stress at the top extreme fibers at the transferee's stage should not exceed $f_{t i}$, while the next equation was used to prevent the stress at the bottom fibers from exceeding $f_{c i}$.

And, the following two equations were used to limit the stresses at top and bottom respectively, within $f_{c}$ and $f_{t}$ at service load conditions.

$$
\begin{aligned}
& \left\{\left[\frac{-\frac{P_{i}}{A_{c}}\left(1-\frac{e_{c} c^{t}}{r^{2}}\right)-\frac{M_{T}}{S^{t}}}{f_{c}}\right]-1\right\} \leq 0.0 \\
& \left\{\left[\frac{-\frac{P_{i}}{A_{c}}\left(1-\frac{e_{c} c_{b}}{r^{2}}\right)-\frac{M_{D}}{S_{b}}}{f_{c i}}\right]-1\right\} \leq 0.0
\end{aligned}
$$

All of the four previous equations were used to control the stresses at mid-span section, the following equations were used to control these stresses at support section (top and bottom respectively).

$$
\begin{aligned}
& \left\{\left[\frac{-\frac{P_{e}}{A_{c}}\left(1-\frac{e_{c} c^{t}}{r^{2}}\right)-0.0}{12 \sqrt{f_{c}^{-}}}\right]-1\right\} \leq 0.0 \\
& \left\{\left[\frac{-\frac{P_{e}}{A_{c}}\left(1-\frac{e_{c} b}{r^{2}}\right)-0.0}{12 f_{c}}\right]-1\right\} \leq 0.0
\end{aligned}
$$

To ensure a tensile stress at the top fibers of the cross section within the allowable limit, the following constraint was used to control the optimum value of the eccentricity at the support section $\left(\mathrm{e}_{\mathrm{e}}\right)$.

$$
\left\{e_{e}-\frac{P_{e}}{A_{c}} \times\left(\frac{-f_{c i} A_{c}}{-P_{i}}-1\right)\right\} \leq 0.0
$$

In order to make sure that the optimum designed section will be symmetrical, the following two equations were used to control the values of $c^{t}$ and $c_{b}$ within a certain limit (summed to the entire height of the section (h)). Also, limiting each of their values to the other.

$$
\begin{aligned}
& {\left[h-\left(c^{t}+e_{e}\right)\right]=0.0} \\
& \left(c^{t}+c_{b}\right)=0.0
\end{aligned}
$$

For the alignment of the tendon, and to attain that the optimum values of the eccentricities of this tendon lies within the zero and the allowable tension zone at different sections along the beam, the lower and the upper envelope which represent the maximum value for these eccentricities, were found by: First, limiting the stresses without causing any tension in the extreme concrete top fibers by:

$-\frac{P_{i}}{A_{c}}\left(1-\frac{e c^{t}}{r^{2}}\right)=0.0$

From this, we can get the value of the lower kern point $k_{b}$, which will be limited by the following design constrain:

$k_{b}-\frac{r^{2}}{c^{t}}=0.0$

By the same way, we can get the upper kern point $k_{t}$, which will be represented by:

$k^{t}-\frac{r^{2}}{c_{b}}=0.0$

Second, for the lower envelope at three sections along the beam (mid-span, quarter-span, and support section), the maximum distance below the bottom kern to prevent tensile stresses at the top extreme fibers will be represented by $\mathrm{a}_{\min }$, the minimum value of the arm of the couple composed of the center of the pressure line (C-line) and the center of the prestressing tendon line (cgc line) due to $M_{D}$ is:

$a_{\min }-\left(\frac{M_{D}}{P_{i}}\right)=0.0$

That will make the bottom eccentricity limited by the following:

$e_{b}-\left(a_{\min }+k_{b}\right)=0.0$

By the same way, the top eccentricity to limit the tensile stresses at the bottom extreme fibers will be represented by the next equation.

$e_{t}-\left(a_{\min }+k^{t}\right)=0.0$

where the minimum distance below the top kern $\left(\mathrm{a}_{\max }\right)$ is:

$a_{\max }-\left(\frac{M_{T}}{P_{e}}\right)=0.0$

Since it is possible to allow the cgc described earlier to fall slightly outside the two limiting cgc envelopes in some codes, an additional eccentricity that causes limited tensile stresses at top and bottom extreme fibers of the cross section can be introduced by the following constraints

$e_{b}^{-}-\left(\frac{f^{(t)} A_{c} k_{b}}{P_{i}}\right)=0.0$

And

$e_{t}^{-}-\left(\frac{f^{(b)} A_{c} k_{t}}{P_{e}}\right)=0.0$

Finally, the optimum eccentricity at three sections should be less than the allowable tension zone which was found by adding the additional eccentricities of top and bottom to the zero tension zone found earlier by limiting the tensile stresses at the extreme fibers of the cross section. In order to conclude that, the following design constraints were used. 
$\left.\begin{array}{l}{\left[\left(\frac{e_{\text {min-span }}}{\left(k_{b}+a_{\text {min }-1}\right)+e_{b}^{-}}\right)-1\right] \leq 0.0} \\ {\left[\left(\frac{e_{\text {quarter-span }}}{\left(k_{b}+a_{\text {min }-1}\right)+e_{b}^{-}}\right)-1\right] \leq 0.0} \\ {\left[\left(\frac{e_{\text {sup-port }}}{\left(k_{b}+a_{\text {min }-1}\right)+e_{b}^{-}}\right)-1\right] \leq 0.0}\end{array}\right\}$

It should be noted that, the maximum distance below the bottom kern point $\left(\mathrm{a}_{\mathrm{min}}\right)$ is calculated with moments according to the location of the section, meaning, for finding $\mathrm{a}_{\min -1}$ the moments are found at mid-span the simply supported beam, $a_{\min -2}$ is calculated with moment equals to $0.75 \mathrm{M}_{\text {mid-span, while no moment was used in }}$ finding $\mathrm{a}_{\min -3}$ which lies at support section.

\section{RESULTS AND DISCUSSION}

\subsection{Checking the Efficiency using PS (MADS)}

To check the validity of the used procedure, the first example was solved using two approaches, the Pattern Search approach and the Genetic Algorithm approach, the results of the two methods were compared to each other with a specific value for applied forces and moments. A simply supported post tensioned I-beam has to carry a super imposed sustained service load moment equals to 7,605,000 in.-1b, and a self-weight moment of 2,490,638 in.-lb, the beam should be designed with variable eccentricity (harped tendon), the time dependent losses of the initial prestress are 18 percent of the initial prestress, and the allowable stresses are as follow:

$f_{c}^{-}=5,000 \mathrm{psi}$

$f_{c i}^{-}=0.75 f_{c}^{-}=3,750 \mathrm{psi}$

$f_{c i}=0.6 f_{c i}^{-}=2,250 \mathrm{psi}$

$f_{t i}=3 \sqrt{f_{c i}^{-}}=183.71 \mathrm{psi}$

$f_{c}=0.45 f_{c}^{-}=2,250 \mathrm{psi}$

$f_{t}=12 \sqrt{f_{c i}^{-}}=848.5 \mathrm{psi}$

And

$f_{p u}=270,000 \mathrm{psi}$

$f_{p e}=\gamma \times 0.7 \times f_{p u}$

$f_{p i}=0.7 \times f_{p u}=0.7 \times 270,000 \mathrm{psi}=189,000 \mathrm{psi}$

$f_{p e}=0.82 \times 0.7 \times 270,000 \mathrm{psi}=154,980 \mathrm{psi}$

$A_{p}=1.99 \mathrm{in}^{2}-$ thirteen $1 / 2$ in

$A_{p}=f_{p i} \times A_{p}=189,000 \times 1.99=376,110 \mathrm{Ib}$

$P_{e}=\gamma \times f_{p i} \times A_{P}$

$P_{e}=0.82 \times 189,000 \times 1.99=376,110 \mathrm{Ib}$

In this example, the optimum section properties were found using PS and GAs with minimum objective function at first. Then, the same example was solved repeatedly for other values of the section properties in order to check the constraints violation.

By using the PS method first, the optimum designed results are shown in Table 1, showing the mesh size change though iterations, in this example the optimum results were gained through 5 iterations as shown in Fig. (3) with objective function equals to -0.0033 . While the constraints violations through iterations are shown in Fig. (4) with nearly zero violation. The optimum section modulus (top and bottom) for this example was equals to 3354.6 in. $^{3}$, as shown in Table 2 with other optimum cross sectional properties

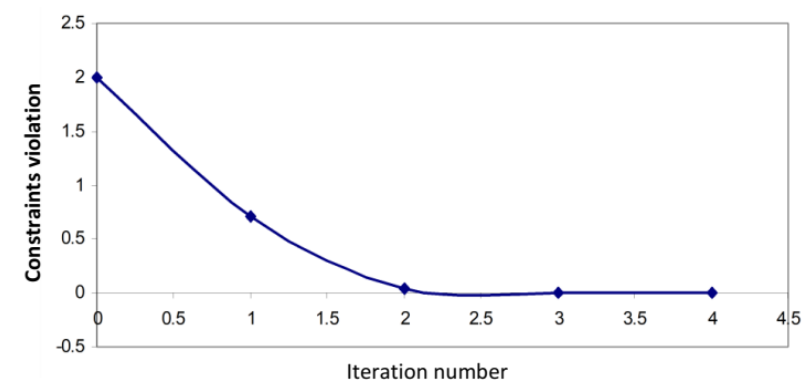

Fig. 4. Maximum constraints violation through iterations of the optimum designed section using PS (MADS).

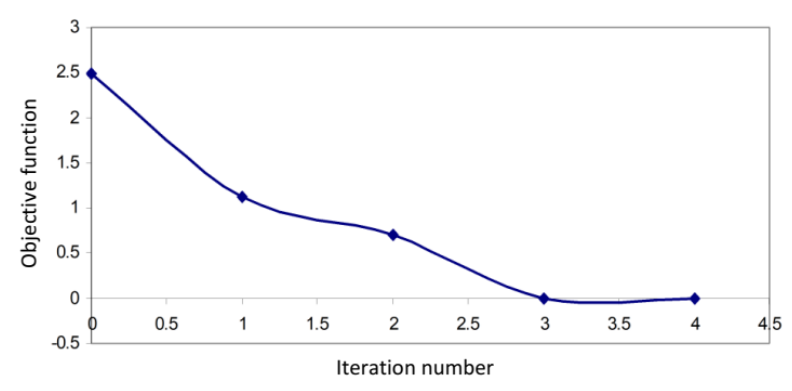

Fig. 3. Objective function through iterations of the optimum designed section using PS (MADS).

Checking the optimum values of the eccentricities at mid-span section $\left(\mathrm{e}_{\mathrm{c}}=17.4756 \mathrm{in}\right.$.) and support section ( $\mathrm{e}_{\mathrm{e}}$ $=10.8524$ in.) in Table 2 , these values should be within the allowable tension zone in order to ensure that the tendon is inside the envelope at all sections along the beam. As it can be seen from this table that the maximum allowable value at mid-span section is 19.6223 as concerning the lower envelope which is greater than the optimum value of $e_{c}$ that was found using PS at that section. Also, the maximum allowable value for $e_{e}$ at support is 13.0002 which is greater than $e_{\mathrm{e}}$ optimum.

\section{Table 1}

Iterations count for optimum designed results using PS (MADS).

\begin{tabular}{lllll}
\hline Iter. & f-count & $\mathbf{f}(\mathbf{x})$ & $\begin{array}{l}\text { Max } \\
\text { Constraints }\end{array}$ & $\begin{array}{l}\text { Mesh } \\
\text { size }\end{array}$ \\
\hline 0 & 1 & 2.49464 & 2 & 1 \\
1 & 46 & 1.12614 & 0.7105 & 0.001 \\
2 & 317 & 0.708536 & 0.03607 & $1 \times 10^{-5}$ \\
3 & 857 & -0.00310975 & 0.0002128 & $1 \times 10^{-7}$ \\
4 & 5597 & -0.00334843 & $9.981 \mathrm{e}-007$ & $1 \times 10^{-9}$ \\
\hline
\end{tabular}

Table 2

Optimum design results using PS (MADS).

\begin{tabular}{ll}
\hline & value \\
\hline $\mathrm{I}\left(\mathrm{in}^{4}\right)$ & 69470 \\
$\mathrm{~h}(\mathrm{in})$ & 41.4171 \\
$\mathrm{C}_{\mathrm{t}}(\mathrm{in})$ & 20.7085 \\
$\mathrm{C}_{\mathrm{b}}(\mathrm{in})$ & 20.7085 \\
$\mathrm{~A}_{\mathrm{c}}\left(\mathrm{in}^{2}\right)$ & 364 \\
$\mathrm{~S}_{\mathrm{t}}\left(\mathrm{in}^{3}\right)$ & 3354.6 \\
$\mathrm{~S}_{\mathrm{b}}\left(\mathrm{in}^{3}\right)$ & 3354.6 \\
$\mathrm{e}_{\mathrm{c}}(\mathrm{in})$ & 17.4756 \\
$\mathrm{e}_{\mathrm{e}}(\mathrm{in})$ & 10.8524 \\
\hline
\end{tabular}


The optimum kern point limits were $\left(\mathrm{k}_{\mathrm{t}}=\mathrm{k}_{\mathrm{b}}=\right.$ 9.2161), the minimum and the maximum arms of the tendon couple were $\left(a_{\min }=6.6221\right.$ in. and $a_{\max }=32.7344$ in), and the optimum additional eccentricities for this example were $\mathrm{e}_{\mathrm{b}}{ }^{-}=3.7841$ and $\mathrm{e}_{\mathrm{t}}{ }^{-}=4.6148$, as shown in Table 3. Fig. 5 shows that these optimum eccentricities are lying within the allowable zone for permitting tension in concrete extreme fiber.

\subsection{Checking the Efficiency using GAs}

Now, by solving the same example using GAs, Table 4 shows the developing of the objective function and the constraints violation through iterations. The objective function was found through 4 iterations and it was equals to -0.0033 with nearly zero constraints violation. While, Table 5 shows the optimum value that were found using this method. Comparing this table with Table 2, a great match between the results found by the two methods PS and GAs. The same goes for Tables 6 and 3 .

Table 3

The cgc envelopes for zero and limited tension zone using PS (MADS).

\begin{tabular}{lllllll}
\hline & \multicolumn{2}{c}{ Mid-span } & \multicolumn{2}{c}{ Quarter-span } & \multicolumn{2}{c}{ Support } \\
\hline & $\begin{array}{l}\text { Lower } \\
\text { envelope }\end{array}$ & $\begin{array}{l}\text { Upper } \\
\text { envelope }\end{array}$ & $\begin{array}{l}\text { Lower } \\
\text { envelope }\end{array}$ & $\begin{array}{l}\text { Upper } \\
\text { envelope }\end{array}$ & $\begin{array}{l}\text { Lower } \\
\text { envelope }\end{array}$ & $\begin{array}{l}\text { Upper } \\
\text { envelope }\end{array}$ \\
\cline { 2 - 7 } Zero tension (in) & 15.8382 & 23.5184 & 14.1826 & 15.3348 & 9.2161 & -9.2161 \\
Increment (in) & +3.7841 & -4.6148 & +3.7841 & -4.6148 & +3.7841 & -4.6148 \\
Allowable tension (in) & 19.6223 & 18.9036 & 17.9668 & 10.72 & 13.0002 & -13.8309 \\
\hline
\end{tabular}

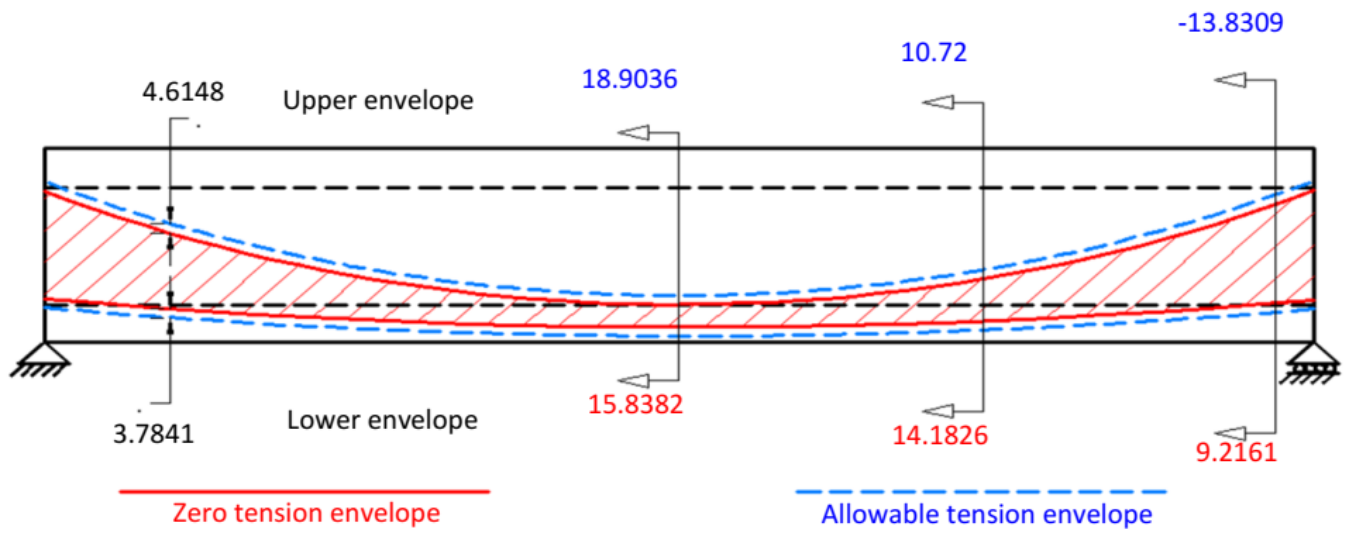

Fig. 5. Optimum envelope in concrete extreme fiber using PS (MADS).

\section{Table 4}

Iterations count for optimum designed results using Gas.

\begin{tabular}{llll}
\hline Iter. & F-count & $\mathbf{f}(\mathbf{x})$ & Max constraints \\
\hline 0 & 6 & 1.22879 & 0.93306 \\
1 & 12 & 0.3455 & 0.000322488 \\
2 & 18 & -0.00737994 & $2.2 \times 10^{-6}$ \\
3 & 24 & -0.0033 & $6.66 \times 10^{-6}$ \\
\hline
\end{tabular}

There are many other sections that gave results which were within the design code limits and with little constraints violation but having a bit higher objective functions than the optimum one using the two methods. The closest results to the optimum design results are shown in Table 7.

The variation of theses objective functions through iterations are shown in Fig. 6 and Fig. 7 for the two methods (PS(MADS) and GAs). While, the variation of the optimum section is shown with a solid line while other sections were drawn with dotted lines.

\section{Table 5}

Optimum design results using Gas.

\begin{tabular}{ll}
\hline item & value \\
\hline $\mathrm{I}\left(\mathrm{in}^{4}\right)$ & 67093 \\
$\mathrm{~h}(\mathrm{in})$ & 40 \\
$\mathrm{C}_{\mathrm{t}}(\mathrm{in})$ & 20 \\
$\mathrm{C}_{\mathrm{b}}(\mathrm{in})$ & 20 \\
$\mathrm{~A}_{\mathrm{c}}\left(\mathrm{in}^{2}\right)$ & 364 \\
$\mathrm{~S}_{\mathrm{t}}\left(\mathrm{in}^{3}\right)$ & 3354.6 \\
$\mathrm{~S}_{\mathrm{b}}\left(\mathrm{in}^{3}\right)$ & 3354.6 \\
$\mathrm{e}_{\mathrm{c}}(\mathrm{in})$ & 17.4756 \\
$\mathrm{e}_{\mathrm{e}}(\mathrm{in})$ & 10.8524 \\
\hline
\end{tabular}

Table 6

The cgc envelopes for zero and limited tension zone using Gas.

\begin{tabular}{lllllll}
\hline & \multicolumn{3}{c}{ Mid-span } & \multicolumn{2}{c}{ Quarter-span } & \multicolumn{2}{c}{ Support } \\
\cline { 2 - 7 } & $\begin{array}{l}\text { Lower } \\
\text { envelope (in) }\end{array}$ & $\begin{array}{l}\text { Upper } \\
\text { envelope (in) }\end{array}$ & $\begin{array}{l}\text { Lower } \\
\text { envelope (in) }\end{array}$ & $\begin{array}{l}\text { Upper } \\
\text { envelope }\end{array}$ & $\begin{array}{l}\text { Lower } \\
\text { envelope }\end{array}$ & $\begin{array}{l}\text { Upper } \\
\text { envelope }\end{array}$ \\
\cline { 2 - 7 } Zero tension & 15.8383 & 23.5183 & 14.1826 & 15.3348 & 9.2162 & -9.2160 \\
Increment & +3.7841 & -4.6148 & +3.7841 & -4.6148 & +3.7841 & -4.6148 \\
Allowable tension & 19.6224 & 18.9035 & 17.9668 & 10.72 & 13.0003 & -13.8308 \\
\hline
\end{tabular}




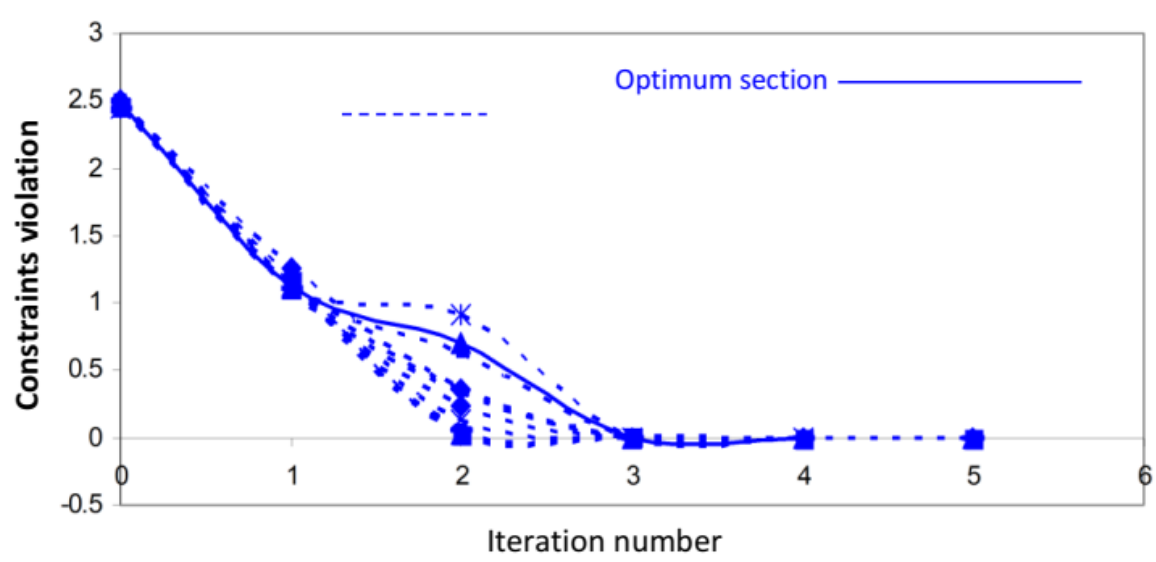

Fig. 6. Objective function through iterations of the other sections using PS (MADS).

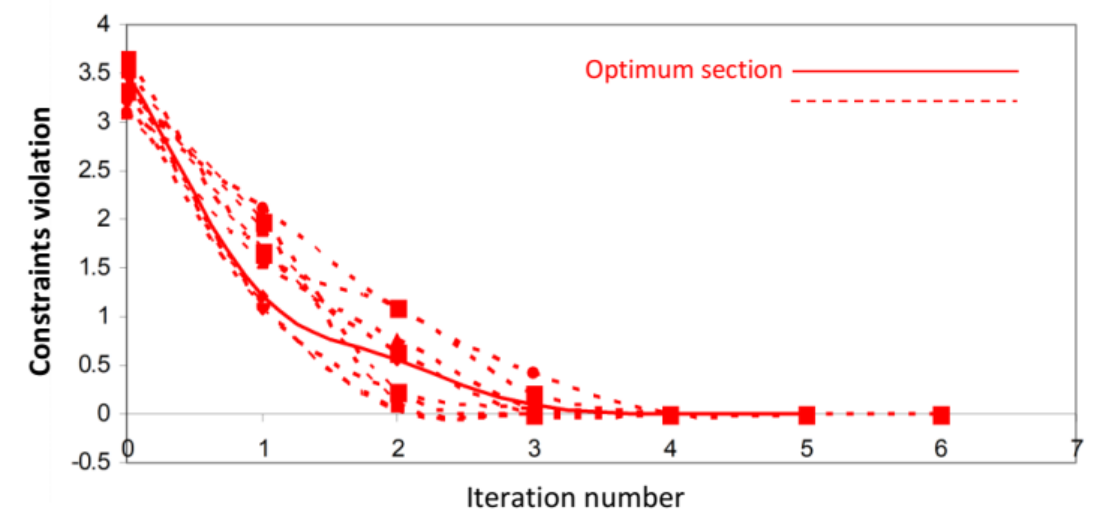

Fig. 7. Objective function through iterations of the other sections using gas.

Table 7

Design results using PS (MADS) and GAs for other sections.

\begin{tabular}{cccccccccc}
\hline $\mathbf{I}\left(\mathbf{i n}^{\mathbf{4}}\right)$ & $\mathbf{h}(\mathbf{i n})$ & $\mathbf{C}_{\mathbf{t}}(\mathbf{i n})$ & $\mathbf{C}_{\mathbf{b}}(\mathbf{i n})$ & $\mathbf{A}_{\mathbf{c}}\left(\mathbf{i n}^{\mathbf{2}}\right)$ & $\mathbf{S}_{\mathbf{t}}\left(\mathbf{i n}^{\mathbf{3}}\right)$ & $\mathbf{S}_{\mathbf{b}}\left(\mathbf{i n}^{\mathbf{3}}\right)$ & $\mathbf{e}_{\mathbf{c}}(\mathbf{i n})$ & $\mathbf{e}_{\mathbf{e}}(\mathbf{i n})$ & Fitness \\
\hline 70442 & 41.9969 & 20.9984 & 20.9984 & 310.0095 & 3354.636 & 3354.636 & 17.4756 & 9.2474 & -0.00348 \\
69299 & 41.3152 & 20.6576 & 20.6576 & 310.6902 & 3354.649 & 3354.649 & 17.4756 & 9.2711 & -0.00342 \\
69794 & 41.6102 & 20.8051 & 20.8051 & 346.7992 & 3354.658 & 3354.658 & 17.4756 & 10.3953 & -0.00344 \\
70406 & 41.9752 & 20.9876 & 20.9876 & 312.3095 & 3354.647 & 3354.647 & 17.4756 & 9.3271 & -0.00348 \\
69179 & 41.2439 & 20.622 & 20.622 & 314.6878 & 3354.621 & 3354.621 & 17.4756 & 9.4082 & -0.00344 \\
68207 & 40.6641 & 20.3321 & 20.3321 & 312.8040 & 3354.646 & 3354.646 & 17.4756 & 9.344 & -0.00346 \\
68211 & 40.6668 & 20.3334 & 20.3334 & 318.066 & 3354.628 & 3354.628 & 17.4756 & 9.5215 & -0.00346 \\
68429 & 40.7967 & 20.3984 & 20.3984 & 309.0752 & 3354.625 & 3354.625 & 17.4756 & 9.2147 & -0.00345 \\
69121 & 41.209 & 20.6045 & 20.6045 & 309.0447 & 3354.655 & 3354.655 & 17.4756 & 9.2136 & -0.00344 \\
69231 & 41.2744 & 20.6372 & 20.6372 & 309.0 & 3354.670 & 3354.670 & 17.4756 & 9.212 & -0.00344 \\
68234 & 40.6801 & 20.3401 & 20.3401 & 308.6201 & 3354.654 & 3354.654 & 17.4756 & 9.1986 & -0.00346 \\
& & & & & GAs & & & & \\
\hline 58507 & 34.8815 & 17.4407 & 17.4407 & 346.796 & 3354.624 & 3354.624 & 17.4756 & 10.3952 & -0.00357 \\
67093 & 40.0 & 20.0 & 20.0 & 300.2239 & 3354.650 & 3354.650 & 17.4756 & 8.8947 & -0.00345 \\
67093 & 40.0 & 20.0 & 20.0 & 300.0 & 3354.650 & 3354.650 & 17.4756 & 8.8863 & -0.00345 \\
67093 & 40.0 & 20.0 & 20.0 & 353.8348 & 3354.650 & 3354.650 & 17.4756 & 10.5877 & -0.00343 \\
67093 & 40.0 & 20.0 & 20.0 & 300.1015 & 3354.650 & 3354.650 & 17.4756 & 8.8901 & -0.00345 \\
67093 & 40.0 & 20.0 & 20.0 & 300.0005 & 3354.650 & 3354.650 & 17.4756 & 8.8863 & -0.00345 \\
67093 & 40.0 & 20.0 & 20.0 & 300.0105 & 3354.650 & 3354.650 & 17.4756 & 8.8867 & -0.00345 \\
71369 & 42.5494 & 21.2747 & 21.2747 & 309.1921 & 3354.641 & 3354.641 & 17.4756 & 9.2188 & -0.00349 \\
67093 & 40.0 & 20.0 & 20.0 & 309.0752 & 3354.650 & 3354.650 & 17.4756 & 9.2147 & -0.00349 \\
\hline
\end{tabular}

\section{CONCLUSIONS}

Although GAs is widely used for optimizing different engineering problems because it can search for many potential solutions at the same time. The PS (MADS) method proved its efficiency in finding the optimum solution of a highly constrained problem such as a post tensioned member with variable eccentricity. Including the eccentricity of the tendon in the optimization procedure increase the time required to solve the problem and indeed make the problem more complex to be solved with multi 
objective functions. It will be more accurate to find the optimum solution that way, and to overcome using other objective functions as design constraints like it was used in this study. Although the two methods found the same optimum solution, other local optimum points were found with solution nearly close to the optimum one. It means that, increasing the used constraints in the design procedure plays a big role in the efficiency and the precision of the optimum designed results. It is recommended that the cost of the designed beam should be included as an objective function, because entering another factor as the cost of the used materials will surely affect the optimum design results in a better way.

\section{ACKNOWLEDGEMENTS}

The author likes to express his sincere appreciations to the reviewers for the time they spent in checking and evaluating this work and for their valuable thoughts to enrich this study.

\section{REFERENCES}

[1] Building code requirements for structural concrete (ACI 318 M-11). ACI Committee 318: USA.
[2] Aydin Z, Ayvaz Y. Overall cost optimization of prestressed concrete bridge using genetic algorithm. Korean Society of Civil Engineers KSCE 2013; 17 (4): 769-776.

[3] De Castilhoa VC, El-Debsa MK, Nicolettib MD. Using a modified genetic algorithm to minimize the production costs for slabs of precast prestressed concrete joists. Engineering Applications of Artificial Intelligence 2007; 20 (4): 519-530.

[4] Lounis Z, Cohn M. Multiobjective optimization of prestressed concrete structures. Journal of Structural Engineering 1993; 119 (3): 794-808.

[5] Aalami BO. Layout of post tensioning and passive reinforcement in floor slabs. pti Post Tensioning Institute USA; 2000: pp. 1-8.

[6] Nawi EG. Prestressed concrete a fundamental approach. USA: Prentice Hall Press; 2015.

[7] Naaman AE. Prestressed concrete analysis and design: Fundamentals. 2nd ed. USA: Techno Press 3000; 2004.

[8] Global optimization tool box 3. User's guide. the math works Inc.

[9] Najem RM, Yousif ST. Optimum structural cost: A genetic algorithms approach. Germany: Scholar's Press, Deutschland; 2015. 